\title{
Letter to the editor on "The therapeutic effect of thymoquinone on acoustic trauma-induced hearing loss in rats"
}

\author{
Alper Yenigun $^{1} \cdot$ Remzi Dogan $^{1} \cdot$ Orhan Ozturan $^{1}$
}

Received: 2 January 2017 / Accepted: 3 February 2017 / Published online: 13 March 2017

(C) Springer-Verlag Berlin Heidelberg 2017

\section{Dear Editor,}

I came across to the article titled "The therapeutic effect of thymoquinone on acoustic trauma-induced hearing loss in rats" by Mahmut Ogurlu et al. which was published in your journal [1], and this article cited our study [2] in their manuscript. The article is well written and I appreciate the effort of the authors. However, it provokes some controversy, which I would like to highlight.

First, the authors have mentioned our study in discussion part of their article by "They used $10 \mathrm{mg} / \mathrm{kg}$ of i.p. TQ, which is lower than our study dose. It should be noted that despite a treatment for 10 days, their post-treatment results were not as good as their pre-trauma results. This may indicate that $10 \mathrm{mg} / \mathrm{kg}$ is not a sufficient dose for full recovery after acoustic trauma" [1]. We believe that the authors have misinterpreted our results. In our study, thymoquinone (TQ) administration was started 1 day before acoustic trauma and was continued for 10 days. It was administered intraperitoneally at a dose of $10 \mathrm{mg} / \mathrm{kg} /$ day [2]. We demonstrated that $10 \mathrm{mg} / \mathrm{kg}$ ip TQ was sufficient, since ABR and DPOAE results at the fifth and tenth days of treatment were similar to pre-trauma measurements demonstrating its reparative effect [2].

This comment refers to the article available at doi:10.1007/ s00405-016-4319-4.

An author's reply to this comment is available at doi:10.1007/ s00405-017-4499-6.

\footnotetext{
Alper Yenigun

alperyenigun@gmail.com

1 Department of Otorhinolaryngology, Faculty of Medicine, Bezmialem Vakif University, Adnan Menderes Bulvarı Vatan Caddesi, Fatih, 34093 Istanbul, Turkey
}

The other point is that AbuKhader has reported in his paper that maximum tolerated dose of TQ that is applied through i.p. is $22.5 \mathrm{mg} / \mathrm{kg}$ for male rats [3]. In this study, they used 20 and $40 \mathrm{mg} / \mathrm{kg}$ of TQ i.p. and they did not perform any biochemical tests to examine the toxicity of TQ.

Finally, the authors have concluded that their study is the second study showing the reparative effect of TQ in trauma acoustic-induced hearing loss. They also emphasized that $20 \mathrm{mg} / \mathrm{kg}$ is sufficient and higher doses are not needed. We demonstrated in our study that $10 \mathrm{mg} / \mathrm{kg}$ of TQ is sufficient for full recovery of acoustic trauma [2]. It was also shown that more than $22.5 \mathrm{mg} / \mathrm{kg}$ is toxic in rats [3]. Thus, we agree with the authors that using higher doses of TQ in the treatment of acoustic trauma on rats is not needed and $10 \mathrm{mg} / \mathrm{kg}$ has already given sufficient results. We wait for the author's contribution and opinion.

Compliance with ethical standards

Conflict of interest All authors declare that they have no conflict of interest.

\section{References}

1. Ogurlu M, Erdivanli OC, Tumkaya L, Ozgur A, Ozergin Coskun Z, Terzi S, Demirci M, Dursun E (2017) The therapeutic effect of thymoquinone on acoustic trauma-induced hearing loss in rats. Eur Arch Otorhinolaryngol 274(2):743-749

2. Aksoy F, Dogan R, Yenigun A, Veyseller B, Ozturan O, Ozturk B (2015) Thymoquinone treatment for inner-ear acoustic trauma in rats. J Laryngol Otol 129(1):38-45

3. Abukhader MM (2012) The effect of route of administration in thymoquinone toxicity in male and female rats. Indian J Pharm Sci 74(3):195-200 